\title{
Modelling of Flexible Vehicle Arresting Systems
}

\author{
Yueqiao Chen, Pak-kin Wong, Zhengchao Xie \\ Department of Electromechanical Engineering \\ Faculty of Science and Technology \\ University of Macau \\ Taipa, Macau
}

\begin{abstract}
As the car bomb incident becomes more prevalent globally, in order to protect people lives and avoid the complete destruction of the suspected vehicle, a promising solution is to use flexible vehicle arresting systems, which generally absorb the kinetic energy of the suspected vehicle using energy absorbers and an arresting net. So the vehicle can be arrested safely. According to the existing literature, theoretical research on vehicle arresting system and process is very little. This research is the first attempt at developing the analytical model for the arresting system and process, and carrying out experimental validation. Based on the model built, dynamic analysis of arresting process was also carried out. Experimental and simulated results indicate the model developed is valid and can accurately predict arresting distance.
\end{abstract}

Keywords-Flexible vehicle arresting system, Analytical model, Computer simulation

\section{INTRODUCTION}

After the "9.11" incident, the survey data was analyzed to identify that the car bomb incident was the majority of these attacks [1]. Consequently, in order to maintain social stability, study on vehicle arresting systems has become important. At present, there are rigid and flexible vehicle arresting systems. Figure 1(a) shows that the rigid system can result in the complete destruction of vehicles and serious threaten to the safety of passengers. In view of the above-mentioned deficiencies of the rigid system, this work studies the flexible vehicle arresting system. Figure 1(b) shows that the kinetic energy of vehicles can be fully absorbed by energy absorbers of flexible systems and slowed down at a smaller deceleration in a safe distance, which can protect the safety of passengers and avoid the complete destruction of vehicles [2].

Currently, there are some patented flexible vehicle arresting systems [3] and their structures are almost the same, as shown in Figure 2. The arresting process of flexible vehicle arresting system is very complex, because a complex space force system is formed in the vehicle by the interaction of various forces, which has an impact on the braking performance of system. According to the authors' best knowledge, no existing research on modeling of any flexible vehicle arresting system. Therefore, in order to analyze the arresting process and performance of system more precisely, this work develops an analytical model for the system and process for the first time, and this newly proposed analytical model can be used for predicting the arresting distance.

\section{ANALYTICAL MODEL OF FLEXIBLE VEHICLE ARRESTING SYSTEM}

The general dynamic model of flexible vehicle arresting system is shown in Figure 3. In the flexible vehicle arresting system, there are two kinds of arresting processes: simple and complex. The simple one is that the contact point is on the runway centerline $\left(\Delta x=0 ; \beta=\beta_{1}=\beta_{2}\right.$; $\left.\mathrm{F}_{\mathrm{b}}=\mathrm{F}_{\mathrm{b} 1}=\mathrm{F}_{\mathrm{b} 2}\right)$. The complex one is that the contact point is off the runway centerline $\left(\Delta x \neq 0 ; \beta_{1} \neq \beta_{2} ; F_{b 1} \neq F_{b 2}\right)$. In this paper, based on the same configuration of Energy Absorber 1 and 2 , the simple case and some related equations are only presented.

Assume the runway center is the origin of the coordinate system and the ground for mounting the arresting system is rigid. The dynamic equation of the arrested vehicle can be directly obtained by:

$$
\frac{\mathrm{mdv}_{\mathrm{y}}}{\mathrm{dt}}=-\left(\mathrm{F}_{\mathrm{z}}+\mathrm{F}_{\mathrm{y}}\right)
$$

In Figure 3, when the contact point is on the runway centerline, the correlation between $\mathrm{F}_{\mathrm{y}}$ and $\mathrm{F}_{\mathrm{b}}$ is:

$$
\mathrm{F}_{\mathrm{y}}=2 \cos \alpha \cos \beta \times \mathrm{F}_{\mathrm{b}}=\frac{2 \mathrm{~S}_{\mathrm{y}}}{\sqrt{\mathrm{H}^{2}+\mathrm{L}^{2}+\mathrm{S}_{\mathrm{y}}^{2}}} \mathrm{~F}_{\mathrm{b}}=2 \mathrm{k}_{\mathrm{v}}\left(\mathrm{S}_{\mathrm{y}}\right) \mathrm{F}_{\mathrm{b}} .
$$

where $\alpha$ is a function of time and

$$
\mathrm{L}=\frac{\mathrm{L}_{\mathrm{r}}-\mathrm{L}_{\mathrm{v}}}{2}
$$

$\mathrm{k}_{\mathrm{v}}\left(\mathrm{S}_{\mathrm{y}}\right)=\cos \alpha \cos \beta=\frac{\mathrm{S}_{\mathrm{y}}}{\sqrt{\mathrm{H}^{2}+\mathrm{S}_{\mathrm{y}}^{2}}} \cdot \frac{\sqrt{\mathrm{H}^{2}+\mathrm{S}_{\mathrm{y}}^{2}}}{\sqrt{\mathrm{H}^{2}+\mathrm{L}^{2}+\mathrm{S}_{\mathrm{y}}^{2}}}=\frac{\mathrm{S}_{\mathrm{y}}}{\sqrt{\mathrm{H}^{2}+\mathrm{L}^{2}+\mathrm{S}_{\mathrm{y}}^{2}}}$.

Moreover, energy absorber as a core of the flexible vehicle arresting system has a direct impact to the arresting performance. In this work, the authors has adopted a common rotary energy absorber whose principle likes a multi-disk clutch, a group of frictional disks produce braking torque and absorb the kinetic energy of the arrested vehicle. And this energy absorber usually has a reel to allow a brake band to wind on it. The reel usually couples with a rotary energy absorbing device which could be single-plate, multiple-disk, external-expanding rim or external-contracting rim brakes. When the system comes into operation, the brake band is able to drive the reel of the energy absorber, the dynamic equation of the energy absorber is:

$$
F_{b} \cdot r-M=J \frac{d \omega}{d t},
$$

where $\mathrm{M}$ can be determined according to the type of rotary energy-absorbing device being used. In this research, $M$ can 
be expressed as:

$$
\mathrm{M}=\frac{2}{3} \pi\left(\mathrm{R}_{\mathrm{e}}^{3}-\mathrm{R}_{\mathrm{i}}^{3}\right) \cdot \mathrm{P} \cdot \mathrm{N} \cdot \mathrm{f}
$$

As the brake band is pulled out from the energy absorber, $r$ and $\mathrm{J}$ in Equation (3) are variables. Based on the structure of the general energy absorber, the equation of $r$ can be obtained by:

$$
\mathrm{r}=\mathrm{r}_{0}+\mathrm{n} \cdot \mathrm{h}=\mathrm{r}\left(\mathrm{S}_{\mathrm{y}}\right)
$$

Furthermore, the moment of inertia of the energy absorber is:

$$
\mathrm{J}=\frac{\mathrm{m}_{\mathrm{d}} \mathrm{r}^{2}}{2}=\mathrm{J}\left(\mathrm{S}_{\mathrm{y}}\right)
$$

The equation of instantaneous rotating mass of the energy absorber is:

$$
m_{d}=m_{p}+A_{b} \cdot L(t) \cdot \rho_{b} .
$$

So the final kinetic equation of the arrested vehicle in simple vehicle arresting process is obtained:

$$
\begin{aligned}
& \left\{m+\frac{2 k_{v}^{2}\left(S_{y}\right) J\left(S_{y}\right)}{r^{2}\left(S_{y}\right)}\right\} \frac{d v_{y}}{d t} \\
& =-\left\{\frac{2 k_{v}\left(S_{y}\right)}{r\left(S_{y}\right)}\left[M+\frac{J\left(S_{y}\right)\left(k_{v}^{\prime}\left(S_{y}\right) r\left(S_{y}\right)-k_{v}\left(S_{y}\right) r^{\prime}\left(S_{y}\right)\right) v_{y}^{2}}{r^{2}\left(S_{y}\right)}\right]+F_{z}\right\}
\end{aligned}
$$

\section{Simulation of ARresting Process in A FleXIBLE VEHICLE ARRESTING SySTEM}

MATLAB 6.5.1 was selected to be the simulation software. The parameters in the simulation model can be modified on the basis of specific arresting condition, and hence the analytical model can be applied to simulate different types of flexible vehicle arresting systems and processes. In this paper, some parameters used in a simulation test are shown in Table.1 where the geometrical and mechanical parameters come from a real vehicle test.

In order to validate the analytical model and the feasibility of system, the simulation of a simple arresting process $\left(\Delta \mathrm{x}=0 ; \beta=\beta_{1}=\beta_{2} ; \mathrm{F}_{\mathrm{b}}=\mathrm{F}_{\mathrm{b} 1}=\mathrm{F}_{\mathrm{b} 2}\right)$ namely Condition 1 was conducted. Moreover, a real vehicle test based on Condition 1 was also conducted under different $\mathrm{v}_{0}$. Table. 2 presents the simulated and experimental results of the arresting distance and the stopping time. Due to limited pages, Figure 4 and Figure 5 only show the simulated and experimental results of vehicle speed $\mathrm{v}_{\mathrm{y}}$, displacement $\mathrm{S}_{\mathrm{y}}$ in Condition 1 under different $\mathrm{v}_{0}=31.4 \mathrm{~km} / \mathrm{h}$ and $\mathrm{v}_{0}=$ $47.5 \mathrm{~km} / \mathrm{h}$.

In Table.2, when $\mathrm{v}_{0}=47.5 \mathrm{~km} / \mathrm{h}$, the maximum error between the experimental arresting distance and the simulated arresting distance is $0.42 \mathrm{~m}$, which is only about $5.39 \%$ difference from the experimental result. The reason for this minor error is that while establishing the analytical model for the arresting process, the influence of air resistance was ignored, but in fact it is a factor affecting the simulated value.

Besides, Figure 4 and Figure 5 show that the simulated $\mathrm{v}_{\mathrm{y}}$, and $\mathrm{S}_{\mathrm{y}}$, are in good agreement with the experimental results. Therefore, the analytical model can effectively predict the arresting distance in different simple vehicle arresting processes.

\section{SUMARRIES}

Up to now, there is no existing research on modeling of flexible vehicle arresting systems. This paper is the first in the literature that reports the development of an analytical model for the general flexible arresting system and process by using the geometrical mapping method and spatial analysis.

To verify the analytical model, a real vehicle test was successfully conducted in order to get experimental data. By comparing the simulated results with the experimental results, it is observed that they are in a very good agreement, which actually verifies the correctness and effectiveness of the proposed model. One conclusion is that using the analytical model can effectively predict the system characteristics in different vehicle arresting processes and systems, especially the arresting distance. It is also believed that the analytical model can assist engineers to design or calibrate a reliable and safe flexible vehicle arresting system for different arrested vehicles.

\section{REFERENCES}

[1] KUCERA, J.; KOCH, A.; SIRAK, M. US Steps up Efforts to Counter Bomb Threats. Jane's Defence Weekly, 2004.

[2] BLIGH, Roger P.; SICKING, Dean L. Applications of Barrier Vii in Design of Flexible Barriers. Transportation Research Record, 1989, No. 1233, PP: 117-123.

[3] BUCKLEY, N. The Design and Testing of a Portable Vehicle Crash Barrier. IEEE Proceedings of the 38th Annual 2004 International Carnahan Conference on Security Technology, 2004, PP: 47-55, New Mexico.

\section{NOMENCLATURE}

$\mathrm{A}_{\mathrm{b}} \quad$ Sectional area of brake band

$\mathrm{f} \quad$ Coefficient of friction of friction disk

$\mathrm{F}_{\mathrm{b}}=\mathrm{F}_{\mathrm{b}}(\mathrm{t}) \quad$ Brake band tension either in Energy Absorber 1

or 2

$\mathrm{F}_{\mathrm{b} 1}=\mathrm{F}_{\mathrm{b} 1}(\mathrm{t}) \quad$ Brake band tension in Energy Absorber 1

$\mathrm{F}_{\mathrm{b} 2}=\mathrm{F}_{\mathrm{b} 2}(\mathrm{t}) \quad$ Brake band tension in Energy Absorber 2

$F_{x}=F_{x}(t) \quad$ Resultant force of $F_{x 1}$ and $F_{x 2}$

$\mathrm{F}_{\mathrm{xl}}=\mathrm{F}_{\mathrm{x} 1}(\mathrm{t}) \quad$ Component of $\mathrm{F}_{\mathrm{b} 1}$ in the $\mathrm{x}$-direction of runway

$\mathrm{F}_{\mathrm{x} 2}=\mathrm{F}_{\mathrm{x} 2}(\mathrm{t}) \quad$ Component of $\mathrm{F}_{\mathrm{b} 2}$ in the $\mathrm{x}$-direction of runway

$\mathrm{F}_{\mathrm{y}}=\mathrm{F}_{\mathrm{y}}(\mathrm{t}) \quad$ Resultant force of $\mathrm{F}_{\mathrm{y} 1}$ and $\mathrm{F}_{\mathrm{y} 2}$

$\mathrm{F}_{\mathrm{y} 1}=\mathrm{F}_{\mathrm{y} 1}(\mathrm{t}) \quad$ Component of $\mathrm{F}_{\mathrm{b} 1}$ in runway direction

$\mathrm{F}_{\mathrm{y} 2}=\mathrm{F}_{\mathrm{y} 2}(\mathrm{t}) \quad$ Component of $\mathrm{F}_{\mathrm{b} 2}$ in runway direction

$\mathrm{F}_{\mathrm{z}} \quad$ Vehicle drag force including tire resistance

$\mathrm{H} \quad$ Height of arresting net

h Thickness of brake band

$\mathrm{J}=\mathrm{J}(\mathrm{t}) \quad$ Moment of inertia of Energy Absorber 1 or 2

$\mathrm{L}(0) \quad$ Maximum length of brake band

$\mathrm{L}(\mathrm{t}) \quad$ Instantaneous residual length of brake band

$\mathrm{L}_{\mathrm{r}} \quad$ Runway width

$\mathrm{L}_{\mathrm{v}} \quad$ Vehicle width

M Braking torque generated from Energy Absorber 


\begin{tabular}{|c|c|c|c|}
\hline $\mathrm{m}$ & Vehicle mass & runway direction & \\
\hline $\mathrm{m}_{\mathrm{d}}=\mathrm{m}_{\mathrm{d}}(\mathrm{t})$ & Instantaneous rotating mass of Energy Absorber & $\mathrm{t}$ & Time \\
\hline 1 or 2 & & $\mathrm{v}_{0}$ & Initial vehicle contact speed \\
\hline $\mathrm{m}_{\mathrm{p}}$ & Mass of energy absorber without brake band & $\mathrm{v}_{\mathrm{y}}=\mathrm{v}_{\mathrm{y}}(\mathrm{t})$ & Vehicle speed in runway direction \\
\hline $\mathrm{n}=\mathrm{n}(\mathrm{t})$ & Instantaneous number of brake band layer on & $\beta=\beta(t)$ & Included angle formed by energy absorber and \\
\hline energy absorber & & vehicle & \\
\hline $\mathrm{N}$ & Number of friction surfaces in energy absorber & $\beta_{1}=\beta_{2}(\mathrm{t})$ & Included angle formed by Energy Absorber 1 \\
\hline $\mathrm{P}$ & Pressure on friction disk & and vehicle & \\
\hline$r=r(t)$ & Effective moment arm of energy absorber & $\beta_{2}=\beta_{2}(\mathrm{t})$ & Included angle formed by Energy Absorber 2 \\
\hline $\mathrm{r}_{0}$ & Effective radius of reel in energy absorber & and vehicle & \\
\hline $\begin{array}{r}\mathrm{R}_{\mathrm{e}} \\
\text { absorber }\end{array}$ & Outer radius of friction surface in energy & $\begin{array}{c}\Delta \mathrm{x} \\
\text { centerlines }\end{array}$ & Offset distance between vehicle and runway \\
\hline $\begin{array}{c}\mathrm{R}_{\mathrm{i}} \\
\text { absorber }\end{array}$ & Inner radius of friction surface in energy & $\begin{array}{r}\theta=\theta(\mathrm{t}) \\
\text { and runway }\end{array}$ & Included angle between vehicle displacement \\
\hline $\begin{array}{l}S_{x}=S_{x}(t) \\
\text { runway }\end{array}$ & Vehicle displacement in the $\mathrm{x}$-direction of & $\begin{array}{l}\rho_{\mathrm{b}} \\
\omega=\omega(\mathrm{t})\end{array}$ & $\begin{array}{l}\text { Density of brake band } \\
\text { Angular velocity of energy absorber }\end{array}$ \\
\hline $\mathrm{S}_{\mathrm{y}}=\mathrm{S}_{\mathrm{y}}(\mathrm{t})$ & ting distance or vehicle displacement in & & \\
\hline
\end{tabular}

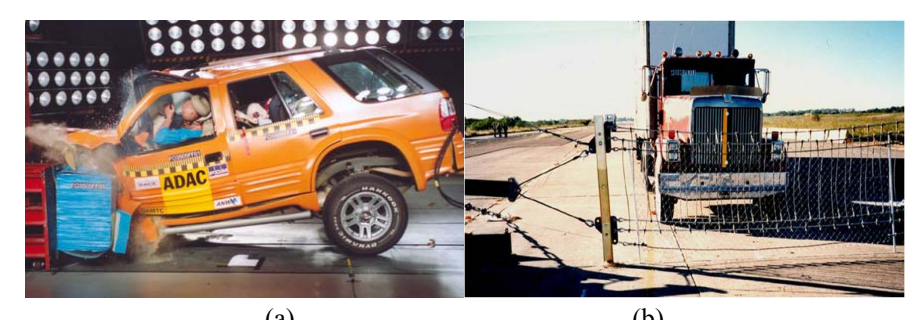

(a)

(b)

Figure 1 Examples of rigid and flexible vehicle arresting systems

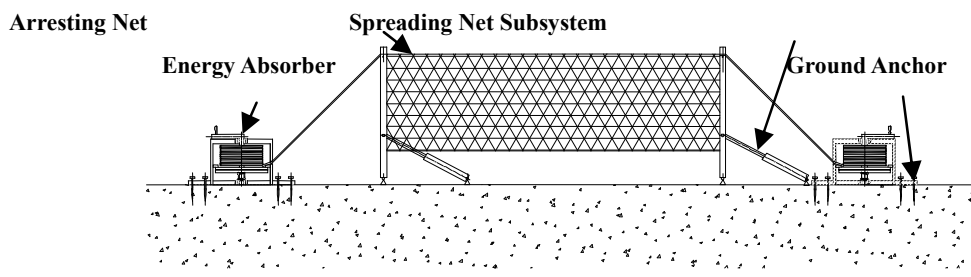

Figure 2 Common structure of flexible vehicle arresting system

TABLE I. PARAMETERS OF ANALYTICAL MODEL FOR SIMULATION

\begin{tabular}{ccccccccc}
\hline $\mathbf{A}_{\mathbf{b}}\left(\mathbf{c m}^{2}\right)$ & $\mathbf{F}_{\mathbf{z}}(\mathbf{N})$ & $\mathbf{h}(\mathbf{m m})$ & $\mathbf{H}(\mathbf{m})$ & $\mathbf{L}(\mathbf{m})$ & $\mathbf{L}(\mathbf{0})(\mathbf{m})$ & $\mathbf{L}_{\mathbf{r}}(\mathbf{m})$ & $\mathbf{L}_{\mathrm{v}}(\mathbf{m})$ & $\mathbf{m}(\mathbf{k g})$ \\
\hline 3.13 & 7350 & 2.98 & 0.92 & 2.25 & 20 & 6.06 & 1.54 & 1506 \\
\hline $\mathbf{M}(\mathbf{N} \cdot \mathbf{m})$ & $\mathbf{m}_{\mathbf{p}}(\mathbf{k g})$ & $\mathbf{N}$ & $\mathbf{P}(\mathbf{M P a})$ & $\mathbf{r}_{\mathbf{0}}(\mathbf{m m})$ & $\mathbf{R}_{\mathbf{e}}(\mathbf{m m})$ & $\mathbf{R}_{\mathbf{i}}(\mathbf{m m})$ & $\mathbf{f}$ & $\mathbf{\rho}_{\mathbf{b}}\left(\mathbf{g} / \mathbf{c m}^{3}\right)$ \\
\hline 3506 & 5.62 & 16 & 0.3 & 139.68 & 115 & 71 & 0.3 & 1.38 \\
\hline
\end{tabular}




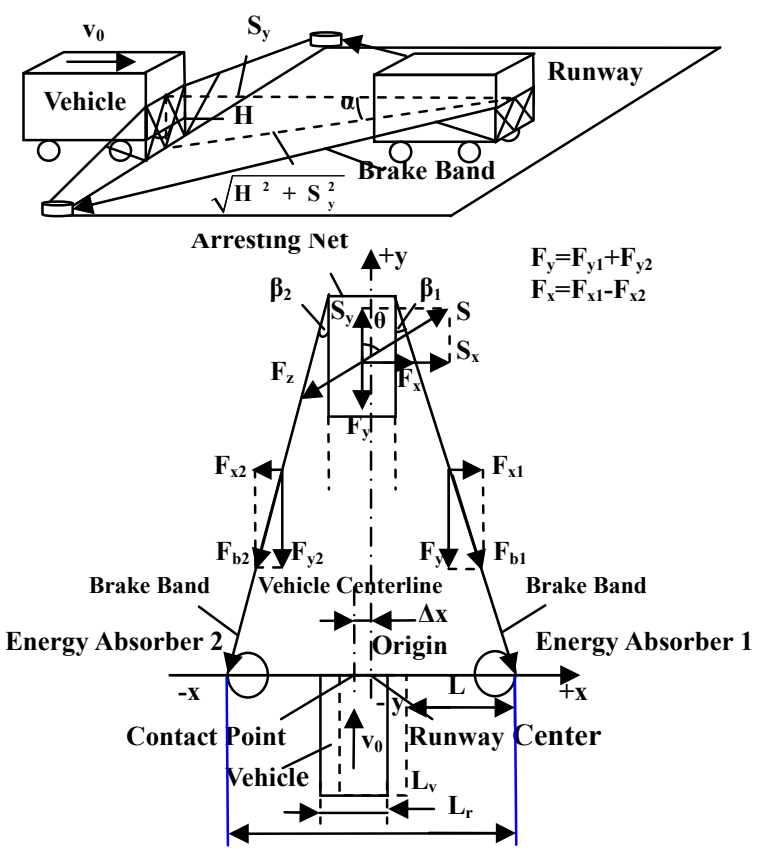

Figure 3 Simplified dynamic model of flexible vehicle arresting system

TABLE. 2 COMPARISON OF REAL VEHICLE TEST AND SIMULATED RESULTS IN CONDITION 1

\begin{tabular}{|c|c|c|c|c|c|c|c|c|}
\hline \multirow{2}{*}{$\mathrm{v}_{0}(\mathrm{~km} / \mathrm{h})$} & \multicolumn{2}{|c|}{$\begin{array}{c}\text { Arresting Distance } \\
\mathrm{S}_{\mathrm{y}}(\mathrm{m})\end{array}$} & \multirow{2}{*}{$\begin{array}{l}\text { Error } \\
(\mathrm{m})\end{array}$} & \multirow{2}{*}{$\begin{array}{c}\text { Percentage } \\
\text { of } \\
\text { Error (\%) }\end{array}$} & \multicolumn{2}{|c|}{ Stopping Time (s) } & \multirow{2}{*}{$\begin{array}{l}\text { Error } \\
(\mathbf{s})\end{array}$} & \multirow{2}{*}{$\begin{array}{c}\text { Percentage } \\
\text { of } \\
\text { Error (\%) }\end{array}$} \\
\hline & $\begin{array}{c}\text { Test } \\
\text { Result }\end{array}$ & $\begin{array}{c}\text { Simulated } \\
\text { Result }\end{array}$ & & & $\begin{array}{c}\text { Test } \\
\text { Result }\end{array}$ & $\begin{array}{c}\text { Simulated } \\
\text { Result }\end{array}$ & & \\
\hline 31.4 & 4.82 & 4.95 & 0.13 & $2.70 \%$ & 1.38 & 1.25 & 0.13 & $9.42 \%$ \\
\hline 34.7 & 5.35 & 5.56 & 0.21 & $3.93 \%$ & 1.47 & 1.37 & 0.1 & $6.8 \%$ \\
\hline 36.7 & 5.74 & 5.98 & 0.24 & $4.18 \%$ & 1.56 & 1.42 & 0.14 & $8.97 \%$ \\
\hline 37.4 & 5.86 & 6.14 & 0.28 & $4.78 \%$ & 1.63 & 1.44 & 0.19 & $11.66 \%$ \\
\hline 47.5 & 7.79 & 8.21 & 0.42 & $5.39 \%$ & 1.75 & 1.73 & 0.02 & $1.14 \%$ \\
\hline
\end{tabular}
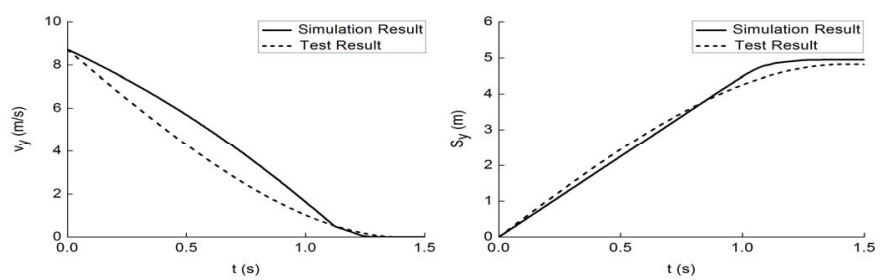

Figure 4 Comparison of system characteristics in Condition $1\left(\mathrm{v}_{0}=31.4 \mathrm{~km} / \mathrm{h}\right)$
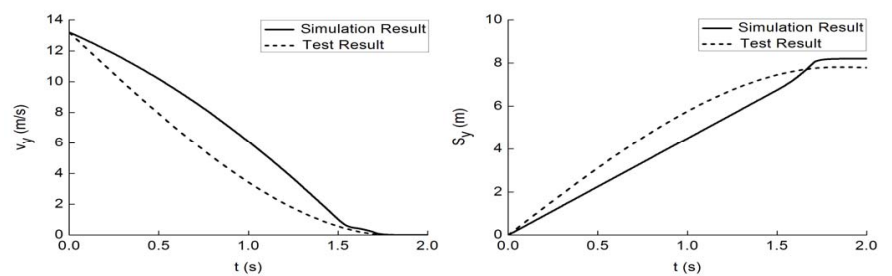

Figure 5 Comparison of system characteristics in Condition $1\left(\mathrm{v}_{0}=47.5 \mathrm{~km} / \mathrm{h}\right)$ 